\title{
DIREITO REGULATÓRIO ESPECÍFICO: CONTROLE PELO BANCO CENTRAL DO BRASIL (BACEN) E PELA UNIDADE DE INTELIGÊNCIA FINANCEIRA DO BRASIL NA PREVENÇÃO E COMBATE À LAVAGEM DE DINHEIRO EM INSTITUIÇÕES FINANCEIRAS
}

\author{
SPECIFIC REGULATORY LAW: CONTROL BY BANCO CENTRAL DO BRASIL \\ (BACEN) AND BY THE BRAZILIAN FINANCIAL INTELLIGENCE UNIT IN \\ PREVENTING AND COMBATING MONEY LAUNDERING IN FINANCIAL \\ INSTITUTIONS
}

\author{
ENOQUE FEITOSA SOBREIRA FILHO ${ }^{1}$ \\ CLAYTON REIS ${ }^{2}$ \\ BEATHRYS RICCI EMERICH ${ }^{3}$
}

\begin{abstract}
RESUMO
O presente trabalho tem o objetivo de abordar o delito da lavagem de dinheiro e seu controle pelo Banco Central do Brasil e pela Unidade de Inteligência Financeira do Brasil. O tema proposto neste estudo "Direito Regulatório Específico: controle pelo Banco Central do Brasil (BACEN) e pela Unidade de Inteligência Financeira do Brasil na prevenção e combate à lavagem de dinheiro em instituições financeiras", tem o objetivo de refletir sobre a criminalidade econômica, dentro da qual a lavagem de capitais está inserida. O delito em comento tem se tornado cada vez mais habitual em todo o mundo e, principalmente no Brasil, envolvendo grandes figuras políticas do país. Sendo assim, uma questão ainda soa muito instigante: "qual a importância da atuação do Banco Central do Brasil e da Unidade de Inteligência Financeira no processo de prevenção e combate à lavagem de dinheiro nas instituições financeiras? ". As razões que tornam importante a realização da pesquisa proposta é a compreensão de compreensão de como a Unidade de Inteligência Financeira do Brasil e o Banco Central do Brasil exercem sua atividade com foco na prevenção e repressão aos crimes de lavagem de capitais e aqueles de cujo proveito econômico os criminosos se utilizam. A metodologia a ser adotada será a dedutiva, isto é, análises de doutrinas, artigos e legislações. Além disso, será empregado o método indutivo devido com a análise de jurisprudências
\end{abstract}

\footnotetext{
${ }^{1}$ Coordenador Nacional do GT "Ética e Cidadania" da Associação Nacional de Pós-Graduação em Filosofia, com mandato até 2020. Fez Graduação em Direito na UFPE. Mestrado em Direito pela mesma instituição. É Doutor em Direito pela UFPE e Doutor em Filosofia pela UFPB. Possui estágio Pós-doutoral em Filosofia do direito pela UFSC. Professor Associado na UFPB, lecionando na Graduação e Pós-Graduação em Direito e em Filosofia. Advogado (licenciado). Professor-visitante da Universidade Eduardo Mondlane (Moçambique). Consultor ad hoc da CAPES. É membro de grupos de pesquisa em diversas I.E.S. do país e no exterior. Líder, no âmbito da UFPB, dos Grupos de Pesquisa "Marxismo e Direito" e "Direito, linguagem jurídica e poder" e "Filosofia do direito", que envolve alunos da graduação e da pós-graduação em Direito e em Filosofia.

2 Pós-doutorado na Faculdade de Direito do Largo São Francisco (USP). Doutor em Direito Tributário pela Pontifícia Universidade Católica de São Paulo (2012). Mestre em Direito Econômico e Social (2004) e Especialista em Direito Empresarial (2000), ambos pela Pontifícia Universidade Católica do Paraná, Bacharel em Direito pela Universidade Federal do Paraná (1994). Professor de Direito Tributário na graduação, especialização, mestrado e doutorado na Faculdade de Direito Curitiba (UNICURITIBA), Professor Convidado no Curso de Posgrado en Derecho Tributario na Universidad Austral de Buenos Aires/Argentina e Ex-professor da Faculdade Autônoma de Direito de São Paulo (2006-2007) e na graduação e especializaçao da Pontifícia Universidade Católica do Paraná (2000-2006/2011-2013).

${ }^{3}$ Mestranda em Direito Empresarial e Cidadania pelo Centro Universitário Curitiba (UNICURITIBA). Possui pós-graduação em Direito Aplicado pela Escola da Magistratura do Paraná (2018). Realizou graduação em Direito pela Pontifícia Universidade Católica do Paraná (2017). Atualmente, é advogada.
} 
acerca do tema até o presente momento. O objetivo geral pretende esclarecer como a Unidade de Inteligência Financeira do Brasil e o Bacen exercem sua atividade com foco na prevenção e repressão aos crimes de lavagem de capitais. E os objetivos específicos pretendem buscar um levantamento histórico acerca do delito de lavagem de capitais, conceituar o delito de lavagem de dinheiro, apontar as finalidades do delito de lavagem de capitais, esclarecer o que dispõe a lei antilavagem, identificar os órgãos responsáveis pela prevenção e combate aos crimes de lavagem de dinheiro e quais suas principais atribuições e, por fim, analisar as prerrogativas da Unidade de Inteligência Financeira do Brasil.

Palavras-chave: Lavagem de Dinheiro; Unidade de Inteligência Financeira; Banco Central do Brasil; Direito Regulatório Específico; insider trading.

\begin{abstract}
:
This article aims to address the crime of money laundering and its control by the Central Bank of Brazil and the Financial Intelligence Unit of Brazil. The theme proposed in this article, "Specific Regulatory Law: the control by the Central Bank of Brazil (BACEN) and the Financial Intelligence Unit of Brazil in preventing and fighting money laundering in financial institutions," aims to reflect on economic crimes that incorporate money laundering. The crime under discussion has become increasingly common around the world, and especially in Brazil, involving major political figures in the country. Thus, a question still sounds very intriguing, "What is the importance of the action of the Central Bank of Brazil and the Financial Intelligence Unit of Brazil in preventing and fighting money laundering in financial institutions?" The reason which makes this research relevant is understanding how the Financial Intelligence Unit of Brazil and the Central Bank of Brazil carry out their activities focused on the prevention and repression of money laundering and the crimes of those who profit from it. The method used in this article is deductive, namely the analysis of doctrines, articles, and legislation. However, the inductive method will also be utilised regarding the analysis of jurisprudence on the subject up to the present. The overall aim is to clarify how the Financial Intelligence Unit of Brazil and the BACEN are acting to prevent and repress money laundering crimes. The specific objectives are to seek a historical survey of money laundering crime, conceptualize it, point out its purposes, clarify what the anti-laundering law provides, identify the bodies responsible for preventing and combating money laundering crimes and their main attributions and, finally, to analyze the prerogatives of the Financial Intelligence Unit of Brazil.
\end{abstract}

Keywords: money laundering; Financial Intelligence Unit; Central Bank of Brazil; Specific Regulatory Law; insider trading.

\title{
1 INTRODUÇÃO
}

O presente trabalho tem o objetivo de abordar em que circunstâncias a atividade empresarial encontra sua liberdade de ação protegida pela Constituição. No mundo todo temos que o engajamento dos governos, autoridades judiciais e entidades da sociedade civil no combate ao branqueamento de capitais, deixa claro o quanto essa prática é nociva a toda coletividade global.

Nesse cenário, faz-se mais do que necessário a constituição de órgãos e entidades voltadas com a finalidade específica da repressão e prevenção da lavagem de dinheiro, com 
capacidade técnica e financeira para coordenar todo um sistema de combate a tal prática abjeta. Nesse viés, foram criadas as Unidades de Inteligência Financeira.

As razões que tornam importante a realização da pesquisa proposta é a compreensão de como a Unidade de Inteligência Financeira do Brasil e o Bacen exercem sua atividade com foco na prevenção e repressão aos crimes de lavagem de capitais e aqueles de cujo proveito econômico os criminosos se utilizam.

Assim, o objetivo geral pretende esclarecer como a Unidade de Inteligência Financeira do Brasil e o Bacen exercem sua atividade com foco na prevenção e repressão aos crimes de lavagem de capitais e aqueles de cujo proveito econômico os criminosos se utilizam.

Apesar de se tratar de um fenômeno socioeconômico antigo, o crime de lavagem de dinheiro acabou se desenvolvendo e ganhando maiores proporções no cenário jurídico, principalmente por conta do tráfico internacional de drogas, tornando-se, assim, objeto de criminalização pela lei penal de todo o mundo. Assim, o Combate à Lavagem de Dinheiro são regidos através de Acordos e Instrumentos Internacionais de Cooperação e leis locais.

Neste trabalho, será analisado o atual estado da legislação brasileira acerca da repressão à lavagem de capitais bem como a forma e os instrumentos de que se utiliza o Banco Central do Brasil e a Comissão de Valores Mobiliários nesse combate.

Assim, na primeira parte deste artigo, será necessário compreender a atuação do antigo COAF, do Banco Central, das Unidades de Inteligência Financeira e das instituições financeiras, considerando-se a utilização do sistema financeiro para a lavagem de dinheiro de forma preponderante a outras modalidades, para a medição da efetividade da atuação dessas entidades. O controle exercido pelas entidades fiscalizadoras e supervisoras, bem como pelos próprios agentes do sistema financeiro.

Em seguida, o trabalho tratará do atual estado da legislação brasileira acerca do combate à lavagem de capitais bem como a forma e os instrumentos de que se utiliza o Banco Central e a Unidade de Inteligência Financeira do Brasil nesse combate. Assim, este trabalho tem como problema de pesquisa identificar "qual a importância da atuação do Banco Central do Brasil e da Unidade de Inteligência Financeira no processo de prevenção e combate à lavagem de dinheiro nas instituições financeiras?".

Feitas essas ponderações introdutórias, pode-se constatar a complexidade e a relevância da questão objetivada neste trabalho, pelo qual não tem o desígnio de esgotar o assunto, mas apenas, de trazer alguns apontamentos iniciais e importantes acerca do direito regulatório específico da atuação de controle pelo Banco Central Do Brasil (BACEN) e pela Unidade de 
Inteligência Financeira do Brasil na prevenção e combate à lavagem de dinheiro em instituições financeiras.

\section{CRIME DE LAVAGEM DE DINHEIRO}

\subsection{BREVE HISTÓRICO}

O crime de lavagem de dinheiro, também denominado branqueamento de capitais, ocorre quando se auferem vantagens ilícitas e estas, através de algumas etapas, tornam-se aparentemente lícitas, o que dá origem ao termo "Lavagem de Dinheiro".

A expressão "Lavagem de Dinheiro" tem origem na década de 20, nos Estados Unidos da América, época em que mafiosos ocultavam o produto de seus crimes, através de lavanderias ${ }^{4}$.

Segundo Sérgio F. Moro ${ }^{5}$, no tocante ao delito de Lavagem de Capitais, a legislação americana, de forma semelhante à nossa, não é explícita quanto à admissão ou não do dolo eventual, e relaciona o crime de lavagem a crimes antecedentes específicos, ainda que o rol seja bastante amplo (2010, p.63).

Assim, no Brasil, por iniciativa do G-7, em 1989, foi criado o Grupo de Ação Financeira (FAFT/GAFI), um organismo intergovernamental que une as unidades de inteligência financeira de vários países e monitora a aplicação efetiva da legislação para o combate à lavagem de dinheiro e outros ilícitos relacionados ao sistema financeiro internacional.

\subsection{LEI N. 12.683/2012}

A Lei 12.683/2012, surgiu alterando a Lei 9.613/98, a qual suprimiu o rol taxativo de crimes antecedentes, fortaleceu o controle administrativo sobre setores sensíveis à reciclagem de capitais e ampliou as medidas cautelares patrimoniais incidentes sobre a lavagem de dinheiro, conforme assevera Renato Brasileiro ${ }^{6}$.

\footnotetext{
${ }^{4}$ CERVINI, Raúl; TERRA DE OLIVEIRA, William; GOMES, Luiz Flávio. Lei de Lavagem de Capitais. São Paulo: Revista dos Tribunais, 1998, p. 18.

${ }^{5}$ MORO, Sérgio Fernando. Crime de lavagem de dinheiro. São Paulo: Saraiva, 2010. p. 63.

${ }^{6}$ LIMA, Renato Brasileiro de. Legislação Criminal Especial Comentada. Salvador: Jus Podivm, 2015, p. 284.
} 
Resumindo, pode-se dizer que a Lei 12.683/2012 teve o objetivo principal de aproximar a lei nacional às recomendações internacionais a respeito do tema. Com as alterações, o rol de destinatários foi ampliado, passando a incluir também consultores, contadores, gestores de recursos, etc.

Além disso, a nova lei eliminou o antigo rol de crimes antecedentes que tipificavam o crime da lavagem de dinheiro. Assim, com a nova redação, quaisquer crimes ou, também, contravenções penais podem ser configuradas como crime antecedente ao branqueamento de capitais ${ }^{7}$.

\subsection{OS DEVERES DE COMPLIANCE E AS PESSOAS OBRIGADAS}

Os artigos 10 e 11 do Sistema de Autorregulação Bancária (SARB) 11/2013 ${ }^{8}$ prevê que algumas "pessoas obrigadas" têm o "dever de compliance". Conforme essa Lei, operações suspeitas devem ser reportadas as autoridades competentes, para que providenciem sua responsabilidade civil ou administrativa.

O descumprimento dos deveres de compliance previstos na Lei de combate à lavagem de dinheiro podem gerar sanções administrativas ao responsável pelo descumprimento. $\mathrm{O}$ artigo 12 da Lei 9.613/98 prevê: (i) multa; (ii) multa pecuniária variável não superior ao dobro do valor da operação, ou ao dobro do lucro real obtido ou presumivelmente obtido pela realização da operação, ou não superior ao valor de vinte milhões de reais; (iii) inabilitação temporária, pelo prazo de até dez anos, para o exercício do cargo de administrador das instituições financeiras; e (iv) cessação ou suspensão da autorização para o exercício de atividade, operação ou funcionamento.

A Lei ainda prevê que a pena de advertência será aplicada a instituição financeira por irregularidade no cumprimento das obrigações estabelecidas nos incisos I e II do artigo 10 e, a pena de multa, deverá ser aplicada as pessoas obrigadas aos deveres de compliance, por culpa ou dolo, quando: (i) deixarem de sanar as irregularidades objeto de advertência, no prazo assinalado pela autoridade competente; (ii) não cumprirem o disposto nos incisos I a IV do artigo 10; (iii) deixarem de atender, no prazo estabelecido, a requisição formulada nos termos

\footnotetext{
${ }^{7}$ BALTAZAR JR., José Paulo. Crimes federais. 10. ed. São Paulo: Saraiva, 2014, p. 1104.

8 NORMATIVO SARB 011/2013. Prevenção e combate à lavagem de dinheiro e ao financiamento do terrorismo. Disponível em: https://www.legiscompliance.com.br/images/pdf/febraban_normativo_\%20sarb_011_2013_pld.pdf. Acesso em: 14 jan. 2020.
} 
do inciso V do artigo 10; (iv) descumprirem a vedação ou deixarem de fazer a comunicação a que se refere o artigo 11 .

\section{3 ÓRGÃOS RESPONSÁ VEIS PELA PREVENÇÃO E COMBATE AOS CRIMES DE LAVAGEM DE DINHEIRO}

\subsection{ATUAÇÃO DO BANCO CENTRAL DO BRASIL}

O Banco Central do Brasil é uma autarquia vinculada ao Ministério da Fazenda. Sua criação se deu com a Lei n. 4.595/1964 para ser a entidade competente para garantir o poder de compra da moeda nacional.

\subsubsection{PRINCIPAIS ATRIBUIÇÕES}

O Bacen é responsável por exercer o controle de crédito; exercer a fiscalização das instituições financeiras; autorizar o funcionamento das instituições financeiras; estabelecer as condições para o exercício de quaisquer cargos de direção nas instituições financeiras; vigiar a interferência de outras empresas nos mercados financeiros e de capitais e controlar o fluxo de capitais estrangeiros no país.

Assim, em concordância com o que aduz a Lei n. 4.595/1964 em seu art. 10, IX ${ }^{9}$, compete ao Banco Central exercer a supervisão e fiscalização das instituições financeiras e aplicar as penalidades previstas.

Nesse viés, explica Figueiredo ${ }^{10}$ :

\footnotetext{
"São as entidades e os órgãos administrativos encarregados de realizar e executar as atividades de regulação estatal do sistema financeiro nacional. Em que pese atuarem precipuamente em atividades executivas de fiscalização, são dotadas de certo grau de competência normativa, a fim de poderem exercer suas funções de reguladores de mercado."
}

9 BRASÍLIA, Lei $\mathbf{n}^{\mathbf{0}} \mathbf{4 . 5 9 5}$, de 31 de dezembro de 1964, art. 10, IX. Disponível em: http://www.planalto.gov.br/ccivil_03/LEIS/L4595.htm. Acesso em 14 jan. 2020.

${ }^{10}$ FIGUEIREDO, Leonardo Vizeu. Lições de direito econômico. ed. 4. Rio de Janeiro: Forense, 2014. 
Dessa forma, a atuação fiscalizatória exigida pela Lei $\mathrm{n}^{\circ}$ 9.613/98 das instituições financeiras caberá diretamente ao Banco Central do Brasil e somente de forma indireta ao COAF.

\subsection{ATUAÇÃO DA COMISSÃO DE VALORES MOBILIÁRIOS}

Com o intuito de combater com mais eficiência a lavagem de dinheiro, a CVM Comissão de Valores Mobiliários editou a Instrução CVM 301/99 e divulgou o Ofício-Circular SIN $n^{\circ} 5 / 2015$. Tal documento expõe o entendimento da área técnica da CVM sobre as principais questões que norteiam e permeiam o combate e a contínua prevenção à lavagem de dinheiro.

Além de uma importante atuação no combate à lavagem de dinheiro, a Comissão de Valores Mobiliários também atua nos casos de insider trading, isto é, é toda a pessoa que, em virtude de fatos circunstanciais, tem acesso a "informações relevantes" relativas aos negócios e situação da companhia.

Insider trading possui, na verdade, a principal função da CVM de zelar, na medida em que não só traz prejuízos diretos aos investidores que estiverem na ponta contrária da operação do insider, mas como cria, também, uma desconfiança generalizada no mercado de capitais como um todo, catalisando, inclusive, uma fuga de investimentos de maneira geral.

No Brasil, entre 24/05/2013 e 10/06/2013, Eike Batista alienou por meio do fundo Centennial Asset Mining Fund LLC (“CAMF”), R\$ 126,6 milhões de ações ordinárias de emissão da OGXP3 (OGX Óleo e Gás Participações S.A.) por R\$ 197,2 milhões.

Durante as alienações, Eike Batista publicou em seu Twitter mensagens otimistas relacionadas as perspectivas de negócios da OGX. Diante disso, a SEP concluiu que o acusado já teria conhecimento da inviabilidade dos Campos, quando realizou a negociação, a caracterizar conduta típica de insider trading, uma vez que a informação relevante somente viria a ser publicada cerca de 20 (vinte dias) depois da última negociação realizada por Eike Batista.

Assim, o Colegiado da CVM decidiu, por unanimidade, votar pela condenação de Eike Batista à:

Multa no valor de R \$ 440.780.423,00, correspondente a duas vezes e meia o montante da perda evitada, pela negociação de ações de emissão da OGX realizadas entre 24/5/2013 e 10/6/2013, de posse de informação relevante ainda não divulgada ao mercado (infração ao disposto no art. $155, \S 1^{\circ}$, da Lei 6.404/76, c/c o art. 13, caput, da Instrução CVM 358). Inabilitação pelo prazo de 7 anos para o exercício do cargo 
de administrador ou de conselheiro fiscal de companhia aberta, de entidade do sistema de distribuição ou de outras entidades que dependam de autorização ou registro na CVM, pela manipulação do preço das ações da OGX (infração ao disposto no item I da Instrução CVM 08). Multa no valor de R\$ 95.725.866,08, correspondente a duas vezes e meia o montante da perda evitada, pela negociação de ações de emissão da OGX e da OSX realizadas entre 27/8/2013 e 3/9/2013, de posse de informação relevante ainda não divulgada ao mercado (infração ao disposto no art. $155, \S 1^{\circ}$, da Lei 6.404/76, c/c o art. 13, caput, da Instrução CVM 358). ${ }^{11}$

Ainda de acordo com a área técnica da CVM, Eike Batista teria induzido os investidores a comprar ações da OGX ao divulgar mensagens otimistas no Twitter, mesmo sabendo de antemão das informações relacionadas ao insucesso da exploração comercial dos Campos, tendo, no entender da SEP, praticado conduta de manipulação de preço das ações da Companhia.

\subsection{UNIDADE DE INTELIGÊNCIA FINANCEIRA DO BRASIL}

Segundo definição atribuída pelo Grupo de Egmont, Unidade Financeira de Inteligência seria uma:

\footnotetext{
“Agência nacional, central, responsável por receber (e requerer), analisar e distribuir às autoridades competentes as denúncias sobre as informações financeiras com respeito a procedimentos presumidamente criminosos conforme legislação ou normas nacionais para impedir a lavagem de dinheiro. "12
}

Além disso, segundo o Grupo de Egmont, o Grupo de Unidades de Inteligência Financeira foi:

"formado com o objetivo de incrementar o apoio aos programas nacionais de combate à lavagem de dinheiro dos países que o integram, e que inclui a ampliação de cooperação entre as UIFs e a sistematização do intercâmbio de experiências e de informações de inteligência financeira, o que melhora a capacidade e a perícia dos

\footnotetext{
${ }^{11}$ RIO DE JANEIRO. Comissão De Valores Mobiliários. Processo Administrativo Sancionador CVM n. RJ2014/0578. Utilização de informações privilegiadas na negociação de ações emissão da da OGX Petróleo e Gás Participações S.A. e da da OSX Brasil S.A. Manipulação de preços de ações de emissão das Companhias. Infração ao art. $155, \S 1^{\circ}$, da Lei ${ }^{\circ}$ 6.404/76 c/c art. 13, caput, da Instrução CVM n n 538/02. Infração ao item II, alínea "b", vedada pelo item I, da Instrução CVM no $08 / 79$. Multas e inabilitação temporária.

Disponível em: http://www.cvm.gov.br/sancionadores/sancionador/2019/20190527_PAS RJ2014-0578.html. Acesso em: 16 jan. 2020.

${ }^{12}$ MINISTÉRIO DA FAZENDA. Lavagem de Dinheiro. Disponível em: http://www.fazenda.gov.br/centrais-deconteudos/publicacoes/cartilhas/arquivos/cartilha-lavagem-de-dinheiro-um-problemamundial.pdf/@ @download/file/Cartilha\%20-\%20Lavagem\%20de\%20dinheiro\%20\%20Um\%20problema\%20mundial.pdf. Acesso em: 14 jan. 2020.
} 
funcionários das unidades e gera melhor comunicação por meio da aplicação de tecnologia específica. "13

Dessa forma, a criação dessas agências de inteligência promoveu o desenvolvimento do Grupo de Egmont que, desde então, possui maior eficiência para desempenhar suas funções e, assim, o resultado dessa ação é a facilitação dos mecanismos de intercâmbio de informações. ${ }^{14}$

Há vários casos que foram submetidos pelas FIU's, porém que não se encaixam nas categorias de lavagem de dinheiro. Ainda assim, esses casos foram considerados interessantes do ponto de vista das FIU's, pois demonstram que bons contatos e a troca de informações entre organizações podem redundar em importantes vitórias no combate às organizações criminosas.

\subsubsection{PREVENÇÃO À LAVAGEM DE DINHEIRO}

Segundo o Ministério da Fazenda, a principal função de uma FIU (Unidade de Inteligência Financeira) é: “estabelecer um mecanismo de prevenção e controle do delito de lavagem de dinheiro através da proteção dos setores financeiros e comerciais passíveis de serem utilizados em manobras ilegais. "15

De acordo com um relatório do Fundo Monetário Internacional (FMI) publicado em 2004, uma unidade de inteligência financeira (UIF ou financial intelligence unit, FIU) é uma entidade nacional centralizada responsável pelo recebimento, análise e transmissão às autoridades competentes de informação estratégica sobre operações econômico-financeiras suspeitas de lavagem de capitais ${ }^{16}$, ou seja, são organismos que recebem informações sobre transações suspeitas de lavagem de capitais fornecidas por instituições financeiras, além de outras entidades e pessoas responsáveis, analisa-as, produzindo relatórios de inteligência, e transmite-os para outros organismos estatais locais de investigação e persecução judicial e, ainda, a outras $\operatorname{UIF}^{17}$.

\footnotetext{
13 Intelect Gerencimento Financeiro. Grupo de Egmont. Disponível em: http://www.igf.com.br/aprende/glossario/glo_Resp.aspx?id=4179. Acesso em: 14 jan. 2020.

${ }^{14}$ MINISTÉRIO DA FAZENDA. Lavagem de Dinheiro. Disponível em: http://www.fazenda.gov.br/centrais-deconteudos/publicacoes/cartilhas/arquivos/cartilha-lavagem-de-dinheiro-um-problemamundial.pdf/@@download/file/Cartilha\%20-\%20Lavagem\%20de\%20dinheiro\%20$\% 20$ Um\%20problema\%20mundial.pdf. Acesso em: 16 jan. 2020.

${ }^{15}$ Ibidem.

${ }^{16}$ Financial Intelligence Units: an Overview. International Monetary Fund, World Bank: Washington D. C., 2004, p. IX. Disponível em: https://www.imf.org/external/pubs/ft/fiu/fiu.pdf. Acesso em: 14 jan. 2020.

17 Financial Intelligence Units, op. cit., p. 04. Disponível em https://www.imf.org/external/pubs/ft/fiu/fiu.pdf. Acesso em 14 jan. 2020. Mais detalhada é a definição construída pelo Grupo de Egmont:

"Egmont Definition. Based upon the work of the Legal Working Group, Egmont approved the following
} 
As instituições financeiras utilizam três técnicas de prevenção e combate à lavagem de dinheiro. A primeira delas é o famoso processo conheça seu cliente (Know your cliente - KYC),

definition of an FIU in 1996, consequently amended in 2004 to reflect the FIU's role in combating terrorism financing:

A central, national agency responsible for receiving, (and as permitted, requesting), analysing and disseminating to the competent authorities, disclosures of financial information: (i) concerning suspected proceeds of crime and potential financing of terrorism, or (ii) required by national legislation or regulation, in order to combat money laundering and terrorism financing.

The definition of an FIU can best be understood through a brief explanation of each of its component parts.

1. A central, national agency. Egmont's focus on international co-operation requires that only one government agency per territory or self-autonomous jurisdiction, recognized by international boundaries, serve as the contact point for international exchanges. It must operate in a jurisdiction that is governed by the laws of that territory. To be clear, use of the phrase 'central, national agency' carries with it no political designation or recognition of any kind. An anti-money laundering/terrorism financing government agency operating in a jurisdiction that in political terms constitutes a dependency of another nation, may be considered an FIU as long as it is the only government agency that carries out these efforts in that internationally recognized boundary. Recognition that such government agency meets the Egmont definition of an FIU does not necessarily equate to sovereignty. In federal systems, the phrase 'central, national agency' implies that only one government agency may be considered an FIU under Egmont. Even though federal systems have multiple subdivisions, only one centralized agency serves as contact point for information exchange for Egmont.

2. Responsible for. This word denotes that the legal framework, which establishes the FIU, authorizes, at a minimum, the functions outlined in the Egmont definition.

3. Receiving, (and as permitted, requesting) analysing and disseminating. This phrase designates the three principal activities of all Egmont FIUs, and the functions that make them unique.

- Receiving. FIUs serve as the central reception point for receiving financial disclosures. This takes into account FIUs that have more than one office and FIUs that receive disclosures from different domestic agencies. This concept also distinguishes FIUs from law enforcement agencies with a general (overall) law enforcement mission. - (And as Permitted, Requesting). Some but not all FIUs have the ability to query specific financial information from certain financial institutions and other non financial entities beyond the financial disclosures that FIUs normally receive from reporting entities. For this reason, the language is in parentheses and is limited in scope.

- Analysing. Analysis involves an initial evaluation of the utility or relevance of disclosures received from reporting entities at the pre-investigation stage. Analysis of information reported to FIUs may occur at different stages and take different forms. Some FIUs analyse every financial disclosure when it arrives at the FIU. For other FIUs, such a system is impossible due to the sheer volume of financial disclosures that they receive. Those FIUs make the financial disclosures immediately available to appropriate investigative authorities and the FIUs analyse financial disclosures in response to requests for information or on their own accord but not in response to each and every financial disclosure reported to it. In an increasing manner, many FIUs have incorporated analytical software that assists in determining money laundering trends and patterns for use by law enforcement, to provide feedback to the reporting institutions and in some cases for purposes of proactive targeting. In all cases, some de minimis level of analysis must occur in order to categorise a given piece of information and determine which agency, or group of agencies, should be entitled to receive it.

- Disseminating. FIUs at a minimum must be able to share information from financial disclosures and the results of their analysis regarding money laundering and related crimes, as determined by domestic legislation, and terrorism financing, firstly with domestic competent authorities and, secondly, with other FIUs. A critical element in assessing dissemination capability involves assessing the extent to which a candidate FIU's law permits the cooperation with other FIUs through the exchange of information.

4. Disclosures of financial information. These are the materials that FIUs use and share with each other to detect and combat money laundering and terrorism financing. In this regard, FIUs may share publicly available and as well as sensitive information (whether financial disclosures or law enforcement information) with competent authorities under terms that protect the information against misuse.

5. Concerning suspected proceeds of crime and potential financing of terrorism. The first type of disclosure of financial information concerns the reporting of suspicious or unusual transactions or activities regarding funds that are suspected of having originated from criminal activity or of being intended to support terrorist activity.

[Disclosures otherwise] required by national legislation, or regulation. This requirement encompasses all other mandated types of reporting requirements required by law, whether involving currency, checks, wires or other transactions.

6. In order to combat money laundering and terrorism financing. This phrase reemphasizes the common purpose of every FIU. 
que permite as instituições financeiras permite conhecer a pessoa jurídica com a qual se esta iniciando uma relação comercial, o que auxilia na identificação de possíveis riscos.

Em seguida, temos o processo das linhas de defesa, em que as instituições organizam seu negócio em três segmentos diferentes, para assim, prevenir e combater a lavagem de dinheiro, sendo elas:

$1^{\mathrm{a}}$ - As áreas de negócio e apoio garantem a aderência de compliance em todas as práticas de negócio (cumprimento de normas);

$2^{\mathrm{a}}$ - A área Jurídico Consultiva interpreta as normas, assessora os administradores e colaboradores no cumprimento do ambiente regulatório e auxilia o compliance no desempenho de suas atividades; e, por fim,

$3^{\mathrm{a}}$ - A área de auditoria avalia periodicamente os riscos de compliance e a eficácia das atividades de compliance corporativo dos Oficiais de Riscos.

E, por fim, a técnica da Governança, Gestão de Risco e Compliance integrados. Esses departamentos elaboram as estratégias do negócio, monitoram as operações todos os dias, realizam auditorias e, desenham e comunicam as políticas adotadas ${ }^{18}$.

\subsection{GRUPO DE AÇÃO FINANCEIRA SOBRE LAVAGEM DE DINHEIRO (GAFI/FATF)}

O Grupo de Ação Financeira sobre Lavagem de Dinheiro (GAFI/FATF) foi criado em 1989 pelos 7 países mais ricos do mundo (G-7) no âmbito da Organização para a Cooperação e Desenvolvimento Econômico (OCDE). A sua principal finalidade é a de examinar, desenvolver e promover políticas de combate à lavagem de dinheiro. ${ }^{19}$

Seu principal objetivo é padronizar os procedimentos para controle da lavagem de dinheiro utilizados pelos países, contando com representantes de 26 governos, dentre eles os maiores centros financeiros do mundo.

\footnotetext{
${ }^{18}$ ANDRADE, Renata Fonseca. Ethics and Compliance Programs in a Global and Brazilian Context: The 6 Principles of Compliance. USA, 2015. Disponível em: http://corporatecomplianceinsights.com/ethics-andcompliance-programs-in-a-global-and-brazilian-context-the-6-principles-of-compliance/. Acesso em: 16 jan. 2020.

${ }^{19}$ MINISTÉRIO DA JUSTIÇA E SEGURANÇA PÚBLICA - Governo Federal. Grupo de Ação Financeira Internacional - GAFI. Disponível em: https://www.justica.gov.br/sua-protecao/cooperacaointernacional/atuacao-internacional-2/foros-internacionais/grupo-de-acao-financeira-internacional-gafi. $\quad$ Acesso em: 16 jan. 2020.
} 


\section{CONSIDERAÇÕES FINAIS}

$\mathrm{Na}$ ementa da Lei $\mathrm{n}^{\mathrm{o}} 12.683 / 2012$, consta que seu objeto é o de alterar a Lei $\mathrm{n}^{\mathrm{o}}$ 9.613/1998 visando a eficiência na persecução penal dos crimes de lavagem de dinheiro.

A existência de uma UIF forte e independente é a chave para prevenir e combater a lavagem de dinheiro. Ao rebaixar seu status institucional e submetê-la a autarquia com atribuições distintas, o governo federal coloca em risco um mecanismo importante para o combate ao crime organizado, seguindo na contramão do mundo e de sua própria diretriz de reforçar a segurança pública.

Além disso, a par de todo o conteúdo e conclusões do presente trabalho, é evidente que será difícil a tarefa da CVM em viabilizar detectações de operações de "insiders", haja vista a capacidade que os participantes do mercado têm de evadir-se da real caracterização das operações que realizam.

As atuações do COAF, do BACEN e das instituições financeiras se revelam, portanto, imprescindíveis para o combate ao branqueamento de capitais e financiamento ao terrorismo e, inclusive, a recuperação e manutenção de uma boa imagem do sistema financeiro, para que as pessoas se sintam seguras ao se aventurar pelo sistema financeiro.

A manutenção de controle das operações tidas por suspeitas pelos agentes reguladores e fiscalizadores, assim como a manutenção de cadastro hígidos dos agentes são alvos de ações corruptíveis e, são essenciais para uma ação preventiva e repressiva à lavagem de dinheiro, bem como à manutenção da própria moralidade do sistema financeiro.

Transitando pela economia, os recursos de origem criminosa criam um mercado artificial, sem qualquer compromisso com o crescimento e o desenvolvimento, além de formarem um poder paralelo, que realimenta o crime e ameaça a ordem democrática.

Como não se atém a fronteiras, a lavagem de dinheiro é um fenômeno mundial, caracterizando-se como um crime transnacional. Por isso, com o passar dos anos a preocupação internacional com a prevenção e o combate à lavagem de dinheiro tem aumentado cada vez mais.

Nesse sentido, como uma das autoridades administrativas encarregadas de promover a aplicação da Lei 9.613/1998, o Banco Central editou normas estabelecendo que as instituições financeiras e demais instituições sob sua regulamentação devem manter atualizados os cadastros dos clientes; manter controles internos para verificar, além da adequada identificação do cliente, a compatibilidade entre as correspondentes movimentações de recursos, atividade econômica e capacidade financeira dos usuários do sistema financeiro nacional; manter 
registros de operações; comunicar operações ou situações suspeitas ao Banco Central; promover treinamento para seus empregados e; implementar procedimentos internos de controle para detecção de operações suspeitas.

Nesse cenário, a atuação o Banco Central, por meio de sua Diretoria de Fiscalização, busca avaliar os controles internos das instituições supervisionadas voltados para a prevenção de ilícitos financeiros, da lavagem de dinheiro e do financiamento do terrorismo, com o objetivo de verificar a adequação e a qualidade dos procedimentos implementados com vistas a coibir a utilização do sistema financeiro para a prática desses ilícitos, bem como de assegurar a observância das leis e regulamentos pelas instituições na execução de suas atividades. 


\section{REFERÊNCIAS}

ALVES DA SILVA, Marcos; ROCHA MEZZADRI, Carlos Eduardo. Breves comentários ao crime de lavagem de dinheiro. Relações Internacionais no Mundo Atual, [S.1.], v. 1, n. 26, p. 164 - 183, abr. 2020. ISSN 2316-2880. Disponível em: 〈http://revista.unicuritiba.edu.br/index.php/RIMA/article/view/3985/371372307>. Acesso em: 25 abr. 2020. doi:http://dx.doi.org/10.21902/Revrima.v1i26.3985.

ANDRADE, Renata Fonseca. Ethics and Compliance Programs in a Global and Brazilian Context: The 6 Principles of Compliance. USA, 2015. Disponível em: http://corporatecomplianceinsights.com/ethics-and-compliance-programs-in-a-global-andbrazilian-context-the-6-principles-of-compliance/. Acesso em: 16 jan. 2020.

BALTAZAR JR., José Paulo. Crimes federais. 10. ed. São Paulo: Saraiva, 2014.

BRASÍLIA, Lei $\mathbf{n}^{\mathbf{0}}$ 4.595, de 31 de dezembro de 1964, art. 10, IX. Disponível em: http://www.planalto.gov.br/ccivil_03/LEIS/L4595.htm. Acesso em 14 jan. 2020.

CERVINI, Raúl; TERRA DE OLIVEIRA, William; GOMES, Luiz Flávio. Lei de Lavagem de Capitais. São Paulo: Revista dos Tribunais, 1998.

FIGUEIREDO, Leonardo Vizeu. Lições de direito econômico. ed. 4. Rio de Janeiro: Forense, 2014.

Financial Intelligence Units: an Overview. International Monetary Fund, World Bank: Washington D. C., 2004, p. IX. Disponível em: https://www.imf.org/external/pubs/ft/fiu/fiu.pdf. Acesso em: 14 jan. 2020.

GUARAGNI, Fábio André; ZAGONEL, Luís Roberto de Oliveira; CARICAT, Fabiana Baptista Silva. Compliance e o direito penal: a adoção de políticas destinadas à diminuição de riscos na atividade empresarial. Percurso, [S.1.], v. 2, n. 21, p. 156 - 161, abr. 2018. ISSN 2316-7521.

Disponível

em:

<http://revista.unicuritiba.edu.br/index.php/percurso/article/view/2608/371371399>. Acesso em: 25 abr. 2020.

GUERRA, Gustavo Rabay; MARCOS, Henrique Jerônimo Bezerra. Legal remarks on the overarching complexities of crypto anti-money laundering regulation. Revista Jurídica, [S.1.], v. 4, n. 57, p. 83 - 115, out. 2019. ISSN 2316-753X. Disponível em: $<$ http://revista.unicuritiba.edu.br/index.php/RevJur/article/view/3757/371372117>. Acesso em: 25 abr. 2020. doi:http://dx.doi.org/10.21902/revistajur.2316-753X.v4i57.3757.

Intelect Gerencimento Financeiro. Grupo de Egmont. Disponível em: http://www.igf.com.br/aprende/glossario/glo_Resp.aspx?id=4179. Acesso em: 14 jan. 2020.

LIMA, Renato Brasileiro de. Legislação Criminal Especial Comentada. Salvador: Jus Podivm, 2015.

MINISTÉRIO DA FAZENDA. Lavagem de Dinheiro. Disponível em: http://www.fazenda.gov.br/centrais-de-conteudos/publicacoes/cartilhas/arquivos/cartilhalavagem-de-dinheiro-um-problema-mundial.pdf/@ @download/file/Cartilha\%20- 
\%20Lavagem\%20de\%20dinheiro\%20-\%20Um\%20problema\%20mundial.pdf. Acesso em: 14 jan. 2020.

MINISTÉRIO DA JUSTIÇA E SEGURANÇA PÚBLICA - Governo Federal. Grupo de Ação Financeira Internacional - GAFI. Disponível em: https://www.justica.gov.br/suaprotecao/cooperacao-internacional/atuacao-internacional-2/foros-internacionais/grupo-deacao-financeira-internacional-gafi. Acesso em: 16 jan. 2020.

MORO, Sérgio Fernando. Crime de lavagem de dinheiro. São Paulo: Saraiva, 2010.

NORMATIVO SARB 011/2013. Prevenção e combate à lavagem de dinheiro e ao financiamento do terrorismo. Disponível em: https://www.legiscompliance.com.br/images/pdf/febraban_normativo_\%20sarb_011_2013_pl d.pdf. Acesso em: 14 jan. 2020.

RIO DE JANEIRO. Comissão De Valores Mobiliários. Processo Administrativo Sancionador CVM n. RJ2014/0578. Utilização de informações privilegiadas na negociação de ações emissão da da OGX Petróleo e Gás Participações S.A. e da da OSX Brasil S.A. Manipulação de preços de ações de emissão das Companhias. Infração ao art. 155, §1 ${ }^{\circ}$, da Lei n ${ }^{\circ} 6.404 / 76$ c/c art. 13, caput, da Instrução CVM n ${ }^{\circ}$ 538/02. Infração ao item II, alínea "b", vedada pelo item I, da Instrução CVM n ${ }^{\text {o }}$ 08/79. Multas e inabilitação temporária. Disponível em: http://www.cvm.gov.br/sancionadores/sancionador/2019/20190527_PAS_RJ2014-0578.html. Acesso em: 16 jan. 2020.

SILVA, Igor Bandeira e; SANTOS, Lorena Batista Alves dos. Foro especial na operação lavajato: mecanismo de impunidade ou proteção do estado?. Percurso, [S.1.], v. 1, n. 20, p. 150 - 156, fev. 2018. ISSN 2316-7521. Disponível em: $\langle$ http://revista.unicuritiba.edu.br/index.php/percurso/article/view/2447/1470>. Acesso em: 25 abr. 2020.

VENTURI, Eliseu Raphael. Justificação jurídica da responsabilidade socioambiental empresarial: racionalidade ambiental das regras pragmáticas à tomada de decisão. Percurso, [S.1.], v. 1, n. 28, p. 373 - 378, jun. 2019. ISSN 2316-7521. Disponível em: $<$ http://revista.unicuritiba.edu.br/index.php/percurso/article/view/3435/371371865>. Acesso em: 25 abr. 2020. 